\title{
Thermal stability of atomic Ag/Au and Au/Ag interfaces on a $\mathrm{Ru}(001)$ substrate
}

Citation for published version (APA):

Wandelt, K., Niemantsverdriet, J. W., Dolle, P., \& Markert, K. (1989). Thermal stability of atomic Ag/Au and $\mathrm{Au} / \mathrm{Ag}$ interfaces on a Ru(001) substrate. Surface Science, 213(2-3), 612-629. https://doi.org/10.1016/00396028\%2889\%2990317-8, https://doi.org/10.1016/0039-6028(89)90317-8

DOI:

10.1016/0039-6028\%2889\%2990317-8

10.1016/0039-6028(89)90317-8

Document status and date:

Published: 01/01/1989

\section{Document Version:}

Publisher's PDF, also known as Version of Record (includes final page, issue and volume numbers)

\section{Please check the document version of this publication:}

- A submitted manuscript is the version of the article upon submission and before peer-review. There can be important differences between the submitted version and the official published version of record. People interested in the research are advised to contact the author for the final version of the publication, or visit the $\mathrm{DOI}$ to the publisher's website.

- The final author version and the galley proof are versions of the publication after peer review.

- The final published version features the final layout of the paper including the volume, issue and page numbers.

Link to publication

\section{General rights}

Copyright and moral rights for the publications made accessible in the public portal are retained by the authors and/or other copyright owners and it is a condition of accessing publications that users recognise and abide by the legal requirements associated with these rights.

- Users may download and print one copy of any publication from the public portal for the purpose of private study or research.

- You may not further distribute the material or use it for any profit-making activity or commercial gain

- You may freely distribute the URL identifying the publication in the public portal.

If the publication is distributed under the terms of Article 25fa of the Dutch Copyright Act, indicated by the "Taverne" license above, please follow below link for the End User Agreement:

www.tue.nl/taverne

Take down policy

If you believe that this document breaches copyright please contact us at:

openaccess@tue.nl

providing details and we will investigate your claim. 


\title{
THERMAL STABILITY OF ATOMIC Ag / Au AND Au / Ag INTERFACES ON A Ru(001) SUBSTRATE.
}

\author{
K. WANDELT, J.W. NIEMANTSVERDRIET *, P. DOLLE ** \\ and K. MARKERT \\ Fritz-Haber-Institut der Max-Planck-Gesellschaft, Faradavweg 4-6, D-1000 Berlin 33. Germany
}

Received 9 August 1988: accepted for publication 20 November 1988

The thermally activated intermixing in $\mathrm{Ag} / \mathrm{Au}$ and $\mathrm{Au} / \mathrm{Ag}$ bilayers supported on a $\mathrm{Ru}(001)$ substrate has been studied using the PAX-technique (photoemission of adsorbed xenon). It is found that the $\mathrm{Ag} / \mathrm{Au}$ interface (on $\mathrm{Ru}$ ) is thermally more stable than the $\mathrm{Au} / \mathrm{Ag}$ interface. In the first case $\mathrm{Ag}$ atoms do not penetrate into the $\mathrm{Au}$ underlayer at $275 \mathrm{~K}$, while in the second case $\mathrm{Au}$ atoms do penetrate into the Ag underlayer at this temperature. These investigations also represent a very successful model study which may be carried over the other metal/metal combinations.

\section{Introduction}

Epitaxial metal monolayers recently attract increasing attention because of their potential technological importance. For instance, epitaxial monolayers of a magnetic material on a non-magnetic substrate like $\mathrm{Fe} / \mathrm{Cu}(100)[1], \mathrm{Fe} /$ $\mathrm{Au}(100)[2]$ may exhibit new magnetic behavior due to an altered geometrical structure and their electronic interaction with the substrate Furthermore, the magnetic moment of e.g. thin $\mathrm{Gd}$ films deposited on $\mathrm{Fe}$ is found to couple antiparallel to that of the substrate [3]. These magnetic properties together with the advantages of thin films like miniaturization and low material consumption make these structures potentially useful for magnetic storage devices. But beyond the mere geometrical and electronical structure of these epitaxial metal/metal interfaces it is also their stability against temperature effects which is of great importance for the design and the technological application of such layered structures. Analytically it is not trivial to demonstrate (or exclude) the onset of site-exchange processes and intermixing across

* Permanent address: Laboratory of Inorganic Chemistry and Catalysis. Eindhoven University of Technology, Eindhoven, The Netherlands.

** Permanent address: Laboratoire de Recherches sur les Interactions Gaz-Solides, CNRS. Villers-Les-Nancy, France.

*** Present address; IBM T.J. Watson Research Center, Yorktown Heights, NY 10598, USA. 
and atomically sharp interface between two metals. In the present paper we demonstrate that the high surface- and site-specificity of the PAX-technique (photoemission of adsorbed xenon) [4] can be taken advantage of to study this problem very successfully. Here we give a full description of model studies, in which we have investigated the thermally activated site exchange between atoms across atomically sharp $\mathrm{Ag} / \mathrm{Au}$ and $\mathrm{Au} / \mathrm{Ag}$ interfaces supported on a $\mathrm{Ru}(001)$ substrate. Part of this work has been written up in a previous short account [5]. Of course, these investigations with the silver-gold system must be regarded as a test study with obvious model character for other metal/metal systems. The results once again prove the surface analytical power of the PAX-technique on the nanometer-scale.

\section{Experimental}

Since the UHV system in which the experiments were carried out has been described in great detail in earlier publications (e.g. refs. [6]) we emphasize here only those technical details which are relevant in the present context. Most importantly, the substrate, a $R \mathbf{u}(001)$ single crystal, was suspended between two thin parallel tungsten wires and connected with a closed-loop helium refrigerator via a gold-plated flexible copper braid [7]. This mounting enabled cooling to $<50 \mathrm{~K}$ as well as resistive heating to $\sim 1500 \mathrm{~K}$. The temperature was measured with a $\mathrm{NiCr}-\mathrm{Ni}$ thermocouple spot-welded directly to the backside of the crystal and served to control the temperature rise in a linear fashion using a feedback circuit [8]. This, in turn, enabled the detection of thermal desorption spectra (TDS) of both adsorbed xenon and the deposited metals, silver and/or gold $[9,10]$, by means of a quadrupole mass-spectrometer.

The surface cleanliness and the crystallographic perfectness of both the $\mathrm{Ru}(001)$ substrate as well as of the initially deposited $\mathrm{Au}$ or $\mathrm{Ag}$ monolayer were verified with Auger electron spectroscopy (AES, CMA) and low energy electron diffraction (LEED), respectively. The cleaning procedure of Ru has been described in great detail in ref. [6]. UV (He I) excited photoemission spectra of xenon adsorbed at $60 \mathrm{~K}$ on the differently prepared surfaces were monitored with a hemispherical electron energy analyzer and stored, analyzed and plotted by means of PDP-computer.

The atomically sharp interfaces between $\mathrm{Ag}$ on $\mathrm{Au}$ and $\mathrm{Au}$ on $\mathrm{Ag}$, respectively, were formed by first preparing just one complete, well annealed monolayer of $\mathrm{Au}$ or $\mathrm{Ag}$ on the clean and perfect $\mathrm{Ru}(001)$ surface, and then depositing at $60 \mathrm{~K}$ a submonolayer amount of the other metal on top. At this low substrate temperature no intermixing and significant atom mobility is expected. Both metals were evaporated from little resistively heated tungsten baskets, and during deposition the pressure remained in the low $10^{-10}$ Torr 
range. The $\mathrm{Ag}$ and $\mathrm{Au}$ coverages, $\theta$, were best determined by the thermal desorption traces of both metals recorded after completion of each experiment. These traces are also a better indicator for the completeness of the respective underlayer [9] than AES, LEED or the confidence in a constant (calibrated) evaporation rate. Both $\mathrm{Au}$ and $\mathrm{Ag}$ do not form alloys with $\mathrm{Ru}$ [5,9-1]; the $\mathrm{Ru}$ surface acts as an infinite diffusion barrier. Hence, after desorption of the respective $\mathrm{Ag}+\mathrm{Au}$ overlayer the $\mathrm{Ru}$ surface was clean and ready for the next experiment.

\section{Results and discussion}

\subsection{Properties of adsorbed xenon}

The first few figures are to recall the principles of the PAX-technique (photoemission of adsorbed xenon). As an overview fig. 1 shows the HeI $(21.22 \mathrm{eV})$ excited angle-integrated UV-photoemission valence band spectrum of a clean $R u(001)$ surface covered with one monolayer (ML) of xenon. Near the onset of electron emission at $E_{\mathrm{F}}$ the spectrum shows some structure from the $\mathrm{Ru}$ valence band; the two sharp and very intense peaks between 5 and 7 $\mathrm{eV}$ below $E_{\mathrm{F}}$ arise from the $5 \mathrm{p}_{3 / 2}$ and $5 \mathrm{p}_{1 / 2}$ photoemission final states of the adsorbed $\mathrm{Xe}$ atoms, and the very intense emission around $15 \mathrm{eV}$ is due to

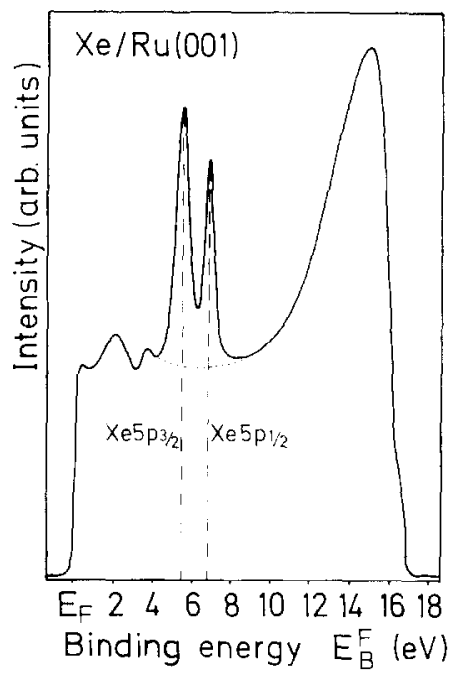

Fig. 1. UV photoemission spectrum of a xenon covered Ru(001) surface excited with IIeI radiation of $21.22 \mathrm{eV}$ photon energy. The two sharp and intense signals between 5 and $7 \mathrm{eV}$ below $E_{\mathrm{F}}$ arise from the $5 \mathrm{p}_{3 / 2}$ and the $5 \mathrm{p}_{1 / 2}$ photoemission final states of adsorbed $\mathrm{Xe}$. The dashed line indicates the substrate background emission. 


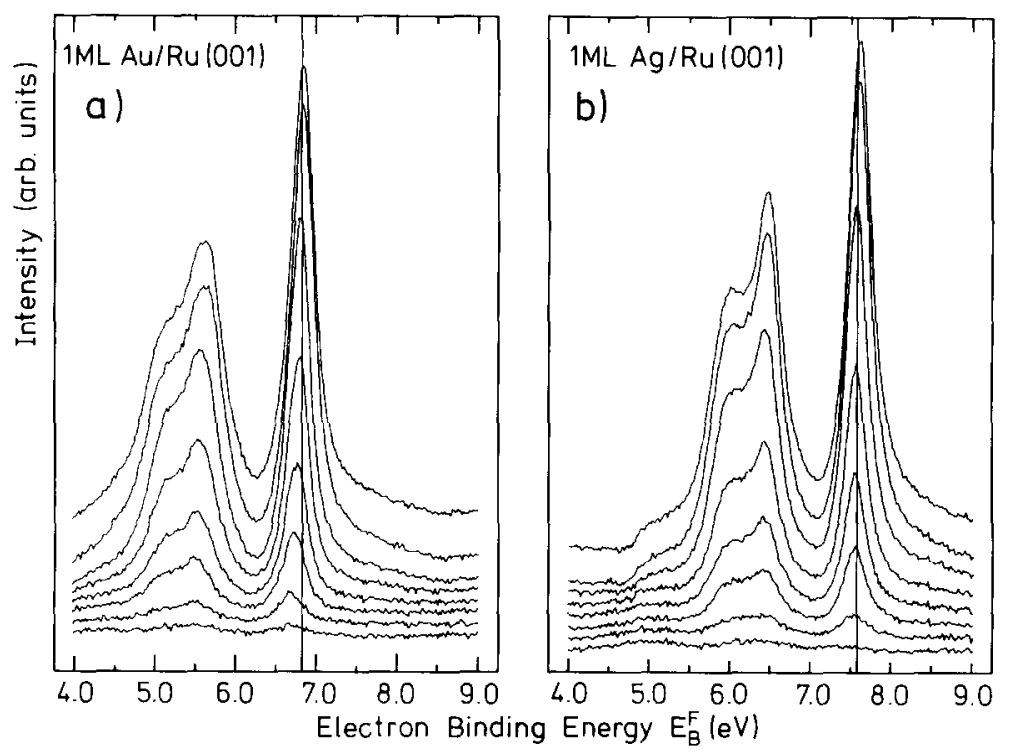

Fig. 2. $5 p_{3 / 2,1 / 2}$ UPS spectra of increasing coverages of Xe on (a) one complete monolayer of gold on $\mathrm{Ru}(001)$ and (b) one complete monolayer of silver on $\mathrm{Ru}(001)$. The substrate background emission (see fig. 1) has been subtracted from each spectrum. The highest spectrum in both panels corresponds to $\mathrm{Xe}$ monolayer saturation.

emission of secondary electrons near threshold. The dashed line indicates the substrate induced background emission under the $\mathrm{Xe} 5 \mathrm{p}_{3 / 2,1 / 2}$ emission. This background is subtracted in all other $\mathrm{Xe} 5 \mathrm{p}_{3 / 2,1 / 2}$ spectra shown throughout this paper.

Гig. 2 shows sets of $\mathrm{Xe} 5 \mathrm{p}_{3 / 2,1 / 2}$ spectra on an expanded energy scale (henceforth called "PAX-spectra") for increasing coverages of Xe adsorbed on (a) a complete and well annealed monolayer of gold on $\mathrm{Ru}(001)$ and (b) a complete and well annealed monolayer of silver on $\mathrm{Ru}(001)$. In both panels the highest spectrum corresponds to a saturated Xe monolayer. The double peak structure of the $5 \mathrm{p}_{3 / 2}$ signal (at lower binding energy) arises mainly from lateral interactions between the adsorbed $\mathrm{Xe}$ atoms and the formation of a two-dimensional (2D) electronic band structure within ordered, densely packed $2 \mathrm{D} \mathrm{Xe}$ islands at submonolayer coverages or in the saturated Xe monolayer [12-14]. Such 2D solid Xe islands of monatomic thickness are only formed on homogeneous, perfectly flat surface patches of sufficient size. Surface defects and adatoms prevent the necessary ordering within the Xe layer. Without discussing this phenomenon any further, in this paper we will use the occurrence of a split $5 \mathrm{p}_{3 / 2}$ signal simply as a fingerprint for the existence of sufficiently large perfect patches on the respective surface, and, hence, as an 
analytical tool for the demonstration of structural order and chemical homogeneity at the surface.

By contrast, the $5 p_{1 / 2}$ signal (at higher electron binding energy; vertical lines in figs. $2 a$ and $2 b$ ) is a single, sharp peak well separated from the $5 p_{3 / 2}$ signal. The width of the $5 \mathrm{p}_{1 / 2}$ peaks is also an indicator for the perfectness of the surface: the more perfect the surface the narrower is the $5 p_{1 / 2}$ peak as will

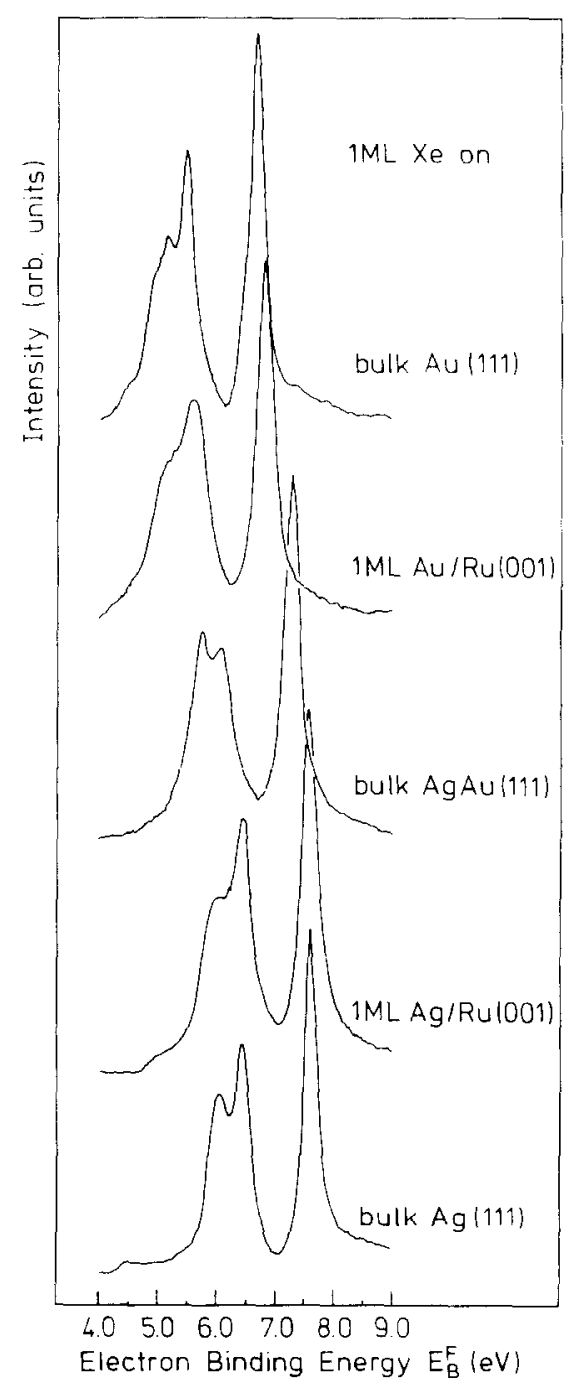

Fig. 3. $\mathrm{Xe}\left(5 \mathrm{p}_{3 / 2,1 / 2}\right)$ reference spectra from $\mathrm{Xe}$ monolayer adsorption on the various indicated single crystal surfaces. Note the different energy positions. 
become obvious from this paper. More important, however, is the position of the $5 \mathrm{p}_{1 / 2}$ signal on the energy axis with respect to the Fermi level, $E_{\mathrm{B}}^{\mathrm{F}}\left(5 \mathrm{p}_{1 / 2}\right)$. On the Au monolayer (fig. 2a) this binding energy is $E_{\mathrm{B}}^{\mathrm{F}}\left(5 \mathrm{p}_{1 / 2}\right)=6.8 \mathrm{eV}$, while on the $\mathrm{Ag}$ monolayer (fig. $2 \mathrm{~b}$ ) a value of $E_{\mathrm{B}}^{\mathrm{F}}\left(5 \mathrm{p}_{1 / 2}\right)=7.55 \mathrm{eV}$ is found. Both values are also very similar to those found on a bulk $A u(111)$ and a bulk $\mathrm{Ag}(111)$ surface, respectively, as shown in fig. 3. The difference $\Delta E_{\mathrm{B}}^{\mathrm{F}}\left(5 \mathrm{p}_{1 / 2}\right)=$ $7.55-6.8 \mathrm{eV}=0.75 \mathrm{eV}$ is due to the work function difference between these two surfaces: $\Delta \phi=\phi_{\mathrm{MLAu}}-\phi_{\mathrm{MLAg}}=5.6-4.75 \mathrm{eV}=0.85 \mathrm{eV}[4,5]$. This correlation $\Delta E_{\mathrm{B}}^{\mathrm{F}} \simeq-\Delta \phi$ has been shown to hold for many pairs of different homogeneous surfaces [4] and constitutes the basis of the PAX-techniques, because it persists also for different sites on heterogeneous surfaces. It enables not only a distinction of Xe atoms adsorbed on Ag- and Au-patches of a surface containing both metals, but also of Xe atoms adsorbed at "mixed" surface sites being in contact with both $\mathrm{Ag}$ and $\mathrm{Au}$ atoms. These "mixed" sites can be of variable composition ( $\mathrm{Ag}: \mathrm{Au}$ ratio) and structure $(\mathrm{Ag}$ and $\mathrm{Au}$ forming a perfect alloy plane (see figs. 3, 6, and 7); $\mathrm{Ag}$ adsorbed on $\mathrm{Au}$; $\mathrm{Au}$ adsorbed on $\mathrm{Ag}$, etc.). Careful reference studies with differently prepared binary $\mathrm{Ag}+\mathrm{Au}$ surfaces have shown, that $E_{\mathrm{B}}^{\mathrm{F}}\left(5 \mathrm{p}_{1 / 2}\right)$ of Xe atoms adsorbed at all these various "mixed" sites ranges from 7.0 to $7.35 \mathrm{eV}$, hence, falls between the positions of $\mathrm{Xe}$ on pure $\mathrm{Au}$ and $\mathrm{Xe}$ on pure $\mathrm{Ag}$ [15]. This becomes evident from the spectrum of $\mathrm{Xe}$ adsorbed on a bulk $\mathrm{Ag}_{0.5} \mathrm{Au}_{0.5}(111)$ alloy surface compared to the pure metal cases as shown in fig. 3 .

Consequently from a heterogeneous surface containing pure Ag-patches, pure Au-patches as well as "mixed" sites, and which is covered with a complete monolayer of Xe, the measured PAX-spectrum is a superposition of $5 p_{3 / 2,1 / 2}$ spectra, each of which is characteristic for one kind of surface site. The partial spectra are shifted with respect to each other by the difference in "local work function" between inequivalent sites. In order to decompose such an integral spectrum cach partial contribution is represented by a set of three Lorentzian lines as depicted in fig. 4. As mentioned above the $5 \mathrm{p}_{3 / 2}$ peak is split into the two photoemission final states $5 \mathrm{p}_{3 / 2}\left(m_{j}= \pm 3 / 2\right)$ and $5 \mathrm{p}_{3 / 2}$ $\left(m_{j}= \pm 1 / 2\right)$, while the $5 \mathrm{p}_{1 / 2}$-peak represents a single final state, $5 \mathrm{p}_{1 / 2}$ $\left(m_{j}= \pm 1 / 2\right)[13]$. The relative intensities and energy separations of the three states are given by the photoemission properties of adsorbed $\mathrm{Xe}$, and therefore are essentially kept constant during the decomposition of a complex integral spectrum into partial PAX-spectra per kind of surface site. Hence, the intensity and the energy position of each partial PAX-spectrum as a whole (consisting of the three Lorentzians as shown in fig. 4) are basically the only variable fit-parameters (see below for more details). The intensity, e.g. of the $5 \mathrm{p}_{1 / 2}$-peak, then is a measure of the relative abundance of the corresponding kind of surface site. The energy position $E_{\mathrm{B}}^{\mathrm{F}}$ of the $5 \mathrm{p}_{1 / 2}$ peak, which is more accurate to determine than those of the $5 \mathrm{p}_{3 / 2}$-signals, provides a determination of the local work function at the respective surface site (patch) [4]. 


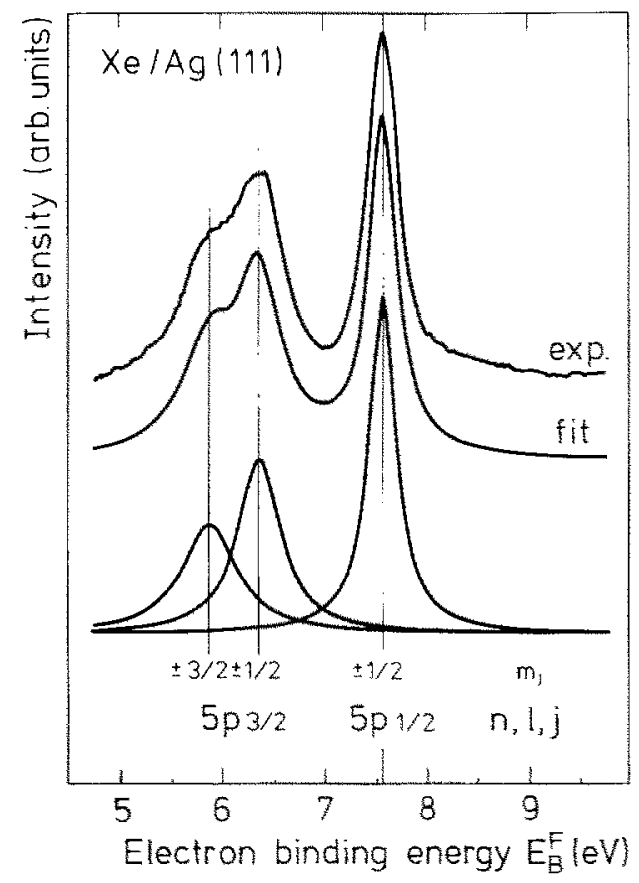

Fig. 4. Experimental $5 \mathrm{p}_{3 / 2.1 / 2}$ UPS spectrum (upper trace) of one complete monolayer of xenon adsorbed on an $\mathrm{Ag}(111)$ single crystal surface. The fit curve corresponds to the best fit with three Lorentzian functions representing the $5 \mathrm{p}_{3 / 2}\left(m_{j}= \pm 3 / 2\right), 5 \mathrm{p}_{3 / 2}\left(m_{j}= \pm 1 / 2\right)$ and $5 \mathrm{p}_{1 / 2}\left(m_{j}=\right.$ $\pm 1 / 2$ ) final states of photoionized adsorbed Xe. $n, l, j, m_{j}=$ quantum numbers. The sharp $5 p_{1 / 2}$ peak is best used for the distinction of different coexisting Xe adsorption states on a heterogeneous surface.

The partial intensity per Xe adsorption state is only a meaningful measure of the relative site concentration if the surface is covered with a complete $\mathrm{Xe}$ monolayer of uniform atomic density. The completeness of the first $\mathrm{Xe}$ monolayer can easily be verified by means of TDS; Xe atoms in the second layer desorb at significantly lower temperatures (e.g. ref. [16]). Also fig. 5 shows that the $\mathrm{Xe} 5 \mathrm{p}_{1 / 2}$ intensity, as determined from a fit-procedure described above, abruptly saturates after an exposure of $11 \mathrm{~L} \mathrm{Xe}$ to the $\mathrm{Ru}(001)$ surface covered with one complete monolayer of Ag. Furthermore, the linear relationship between intensity and exposure indicates a constant Xe sticking coefficient up to saturation of the first $X e$ monolayer at $11 \mathrm{~L}^{\# 1}$. On flat surfaces the packing density of the adsorbed Xe atoms in a complete monolayer is always similar to a $\mathrm{Xe}(111)$ plane, more or less independent of the

*1 The exposures in terms of $1 \mathrm{~L}=10^{-6}$ Torr $\&$ given throughout this paper are not corrected for the ion gauge factor for $X \mathrm{e}$. 


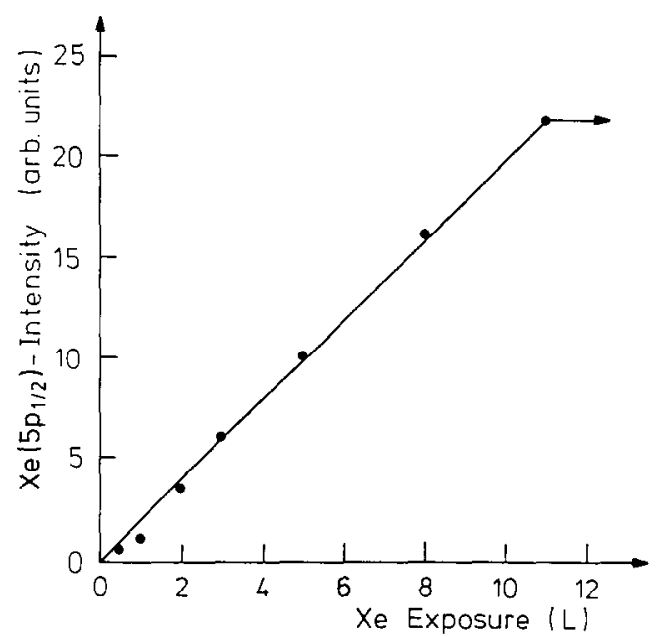

Fig. 5. Plot of the partial $5 p_{1 / 2}$ intensity resulting from a fit as shown in fig. 4 as a function of Xe exposure to an $\mathrm{Ag}(111)$ surface at $60 \mathrm{~K}$. The linear rise suggests a constant sticking coefficient up to Xe monolayer saturation at $11 \mathrm{~L}\left(1\right.$ langmuir $(\mathrm{L})=10^{-6}$ Torr $\left.\cdot \mathrm{s}^{1}\right)$.

surface periodicity. Structural surface imperfections, however, prevent perfect ordering within the Xe overlayer, because defects are sites of higher coordination and, hence, of higher adsorption energy. They are preferred adsorption sites and therefore act as heterogeneous nucleation centers. The resultant disorder in the $\mathrm{Xe}$ overlayer may lead to a moderate scatter in the monolayer capacity (Xe atoms $/ \mathrm{cm}^{2}$ ), which, however, may be roughly estimated from Xe TDS spectra.

\subsection{Characterization of $(A g+A u)$-films on $R u(001)$}

\subsubsection{PAX-spectra - qualitative aspects}

With the adsorption and photoemission properties of $X e$ in mind we can now turn to a discussion of the PAX-spectra obtained from differently prepared and treated binary $(\mathrm{Ag}+\mathrm{Au})$-layers on $\mathrm{Ru}(001)$. We begin with a series of experiments, in which the $\mathrm{Ru}(001)$ surface was first covered with a complete well annealed monolayer of $\mathrm{Ag}$, which then was covered with $0.3 \mathrm{ML}$ $\mathrm{Au}$ at $60 \mathrm{~K}$ and heated to successively increasing temperatures for $10 \mathrm{~min}$ each time. Fig. 6 displays four sets of PAX-spectra. The spectra from fig. $6 \mathrm{a}$, were obtained after the $0.3 \mathrm{ML} \mathrm{Au} / 1 \mathrm{ML}$ Ag overlayer ("/" stands for "on") was warmed up to $275 \mathrm{~K}$ for $10 \mathrm{~min}$ and then recooled to $60 \mathrm{~K}$. Note the lack of any $5 \mathrm{p}_{1 / 2}$-intensity at $E_{\mathrm{B}}^{\mathrm{F}}=6.8 \mathrm{eV}$ (vertical line) which excludes unambiguously the existence of pure Au-sites (patches) on the surface. The single $5 p_{1 / 2}$ peak is at most somewhat asymmetric and its position shifts from $7.1 \mathrm{eV}$ at 

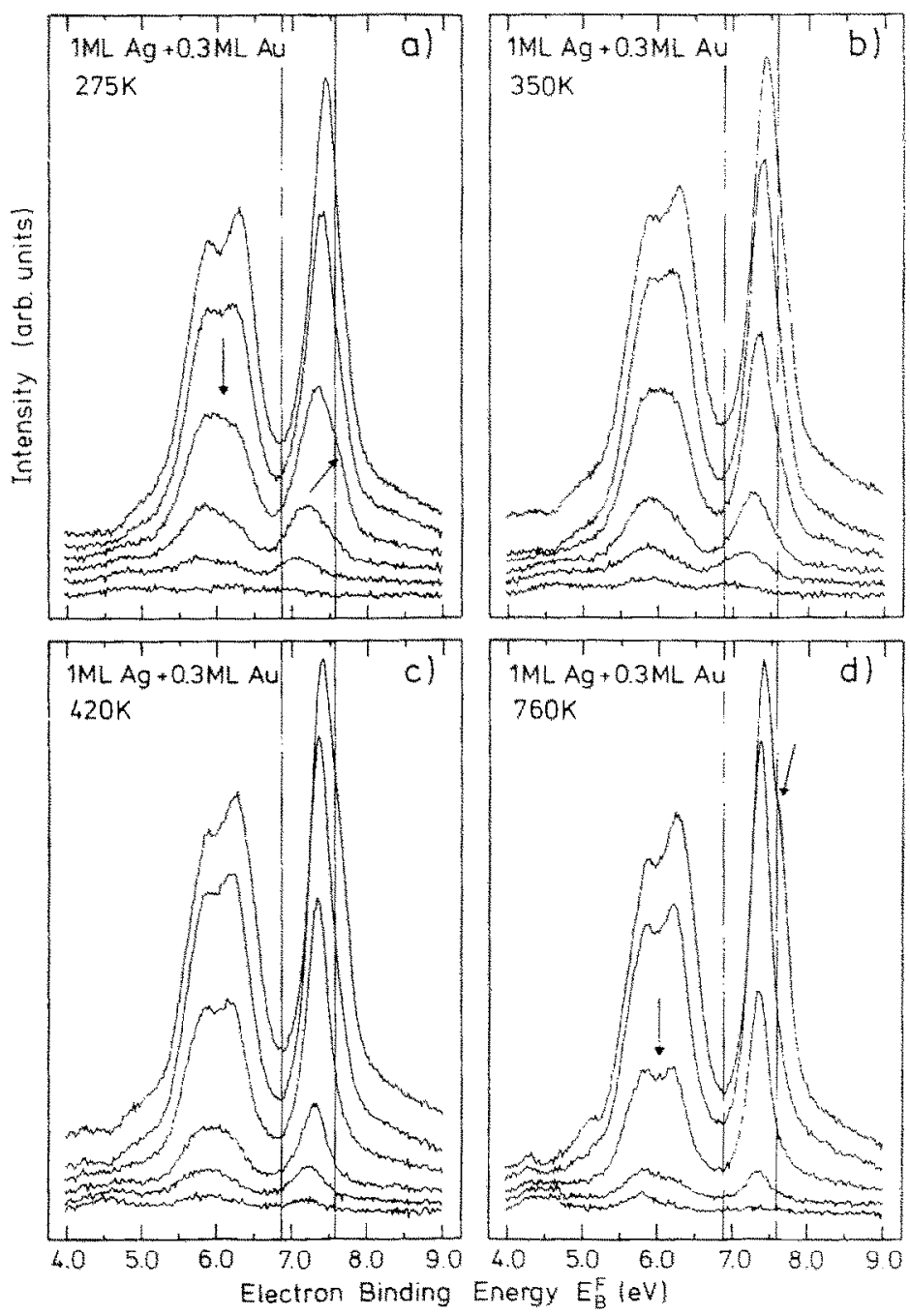

Fig. 6. Xe(5 $\left(5 \mathrm{p}_{3 / 2,1 / 2}\right)(=\mathrm{PAX})$ spectra for different coverages of Xe adsorbed at $60 \mathrm{~K}$ on a complete monolayer of $\mathrm{Ag}$ (on a $\mathrm{Ru}(001)$ substrate) which was covered with $0.3 \mathrm{ML}$ Au at $60 \mathrm{~K}$ following by annealing for $10 \mathrm{~min}$ at (a) 275 , (b) $350 \mathrm{~K}$, (c) $420 \mathrm{~K}$, and (d) $760 \mathrm{~K}$. Note the spectral changes as a function of annealing treatment in particular at low Xe coverages, which are related to structural transformations at the surface. The highest spectrum in each panel corresponds to a saturated Xe monolayer.

low Xe coverage to $7.45 \mathrm{eV}$ at $\mathrm{Xe}$ monolayer saturation (highest spectrum). The evolution of this peak asymmetry (arrow) at intermediate Xe coverage suggests the growth of new Xe states at the higher binding energy side, which 
leads to the overall shift of the peak maximum. The $5 \mathrm{p}_{3 / 2}$ peak splits only visible at higher Xe coverages. Since the total coverage of $\theta_{\mathrm{Ag}}+\theta_{\mathrm{Au}}=1.3 \mathrm{ML}$ implies only a fractional second layer, the surface will comprise step-sites, namely the boundary-sites of islands or small 2D clusters. These step-sites are "decorated" first by Xe atoms and prevent the formation of 2D Xe islands, which explains the poor splitting of the $5 \mathrm{p}_{3 / 2}$ peak at lower Xe coverages. Furthermore, these step-sites obviously involve Au atoms as suggested by the low binding energy $E_{\mathrm{B}}^{\mathrm{F}}$ of the $5 \mathrm{p}_{1 / 2}$ signal. Only with increasing Xe coverage the remaining pure $\mathrm{Ag}$-patches from the original $\mathrm{Ag}$ monolayer are populated causing the $5 p_{3 / 2}$ splitting and the $5 p_{1 / 2}$ shift to higher binding energies.

Further annealing of the $0.3 \mathrm{ML} \mathrm{Au} / 1 \mathrm{ML} \mathrm{Ag}$ film for $10 \mathrm{~min}$ at $350 \mathrm{~K}$ (fig. 6b) and $420 \mathrm{~K}$ (fig. 6c), respectively, causes only minor changes of the resultant PAX-spectra. The $5 \mathrm{p}_{1 / 2}$ peak sharpens up; at low Xe coverages $\left(E_{\mathrm{B}}^{\mathrm{F}}\left(5 \mathrm{p}_{1 / 2}\right)\right.$ is higher than in fig. $6 \mathrm{a}$, and the $5 \mathrm{p}_{3 / 2}$ signals begin to split at lower Xe coverages. All three trends support a progressive homogenization of the surface sites populated first by Xe (low coverages) as well as a growth of the metal islands in the second layer. Even annealing at $760 \mathrm{~K}$ for $10 \mathrm{~min}$ (fig. 6d) causes hardly any further change, except one important detail: At $\mathrm{Xe}$ monolayer saturation (highest spectrum) the $5 \mathrm{p}_{1 / 2}$ peak exhibits a well resolved shoulder (arrow) near the binding energy characteristic of $\mathrm{Xe}$ on pure Ag. Qualitatively, the PAX-spectra from figs. 6a-6d support the notion that already at $275 \mathrm{~K}$ the $\mathrm{Au}$ atoms (originally deposited on top of a complete $\mathrm{Ag}$ monolayer) have started to penetrate into the $\mathrm{Ag}$ underlayer, because no $\mathrm{Xe}\left(5 \mathrm{p}_{1 / 2}\right)$ peak from pure Au-sites is observed. An equivalent number of $\mathrm{Ag}$ atoms is displaced into the second layer thereby producing a rough surface with high-coordination (step-) sites. With increasing annealing temperature more $\mathrm{Au}$ atoms are dissolved homogeneously in the first layer (in contact with $\mathrm{Ru}$ ) and more $\mathrm{Ag}$ atoms form increasingly growing $\mathrm{Ag}$ islands in the second layer.

Before we draw even more detailed conclusions from a careful quantitative decomposition of the spectra shown in figs. $6 \mathrm{a}-6 \mathrm{~d}$, we shall first describe the PAX-spectra observed from a second series of experiments in which the order of $\mathrm{Ag}$ and $\mathrm{Au}$ deposition was reversed. First a complete and well annealed $\mathrm{Au}$ monolayer was prepared onto which $0.5 \mathrm{ML} \mathrm{Ag}$ were deposited at $60 \mathrm{~K}$. At this low substrate temperature the $\mathrm{Ag}$ atoms are basically immobile and remain statistically distributed across the Au underlayer, thereby producing a large number of high-coordination sites around them. The resultant PAX-spectra are displayed in fig. $7 \mathrm{a}$. The initial $5 \mathrm{p}_{1 / 2}$ peak is rather broad and grows between the positions of $\mathrm{Xe}$ on pure $\mathrm{Au}$ or pure $\mathrm{Ag}$, respectively (vertical lines), which is characteristic of "mixed" sites. These sites correspond to the high-coordination, next-nearest neighbor sites of the Ag atoms because they are populated first (low Xe coverage). At intermediate Xe coverage a $5 \mathrm{p}_{1 / 2}$ peak suddenly emerges at $6.8 \mathrm{eV}$ characteristic for $\mathrm{Xe}$ on pure Au while the 

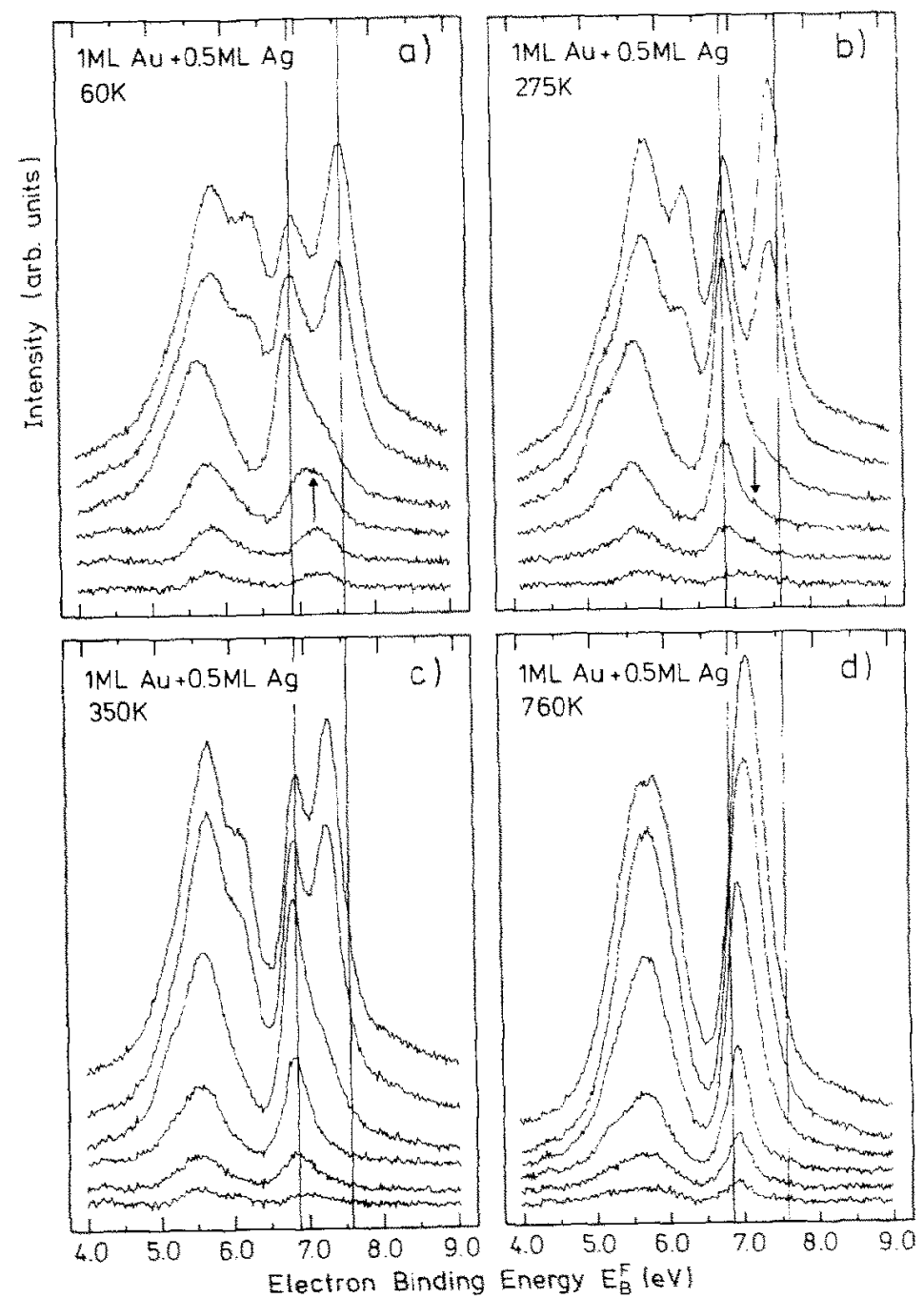

Fig. 7. $\mathrm{Xe}\left(5 \mathrm{p}_{3 / 2, \mathrm{i} / 2}\right)(=\mathrm{PAX})$ spectra for different coverages of $\mathrm{Xe}$ adsorbed at $60 \mathrm{~K}$ on a complete monolayer of $\mathrm{Au}$ (on a Ru(001) substrate) which was covered with $0.5 \mathrm{ML} \mathrm{Ag}$ at $60 \mathrm{~K}$ (panel (a)) followed by annealing for $10 \mathrm{~min}$ at (b) $275 \mathrm{~K}$, (c) $350 \mathrm{~K}$ and (d) $760 \mathrm{~K}$. Note the strong spectral changes of the $5 \mathrm{p}_{1 / 2}$ signal as a function of annealing temperature for both low and high $\mathrm{Xe}$ coverages. These changes are indicative of thermally activated structural and chemical redistributions at the surface. The highest spectrum in each panel corresponds to Xe monolayer saturation.

original intensity from "mixed" sites remains visible as a shoulder. Further increase of the Xe coverage causes the appearance of a second $5 p_{1 / 2}$ peak in the position for $\mathrm{Xe}$ on pure $\mathrm{Ag}$ with $E_{\mathrm{B}}^{\mathrm{F}}=7.55 \mathrm{eV}$. At no stage in fig. 7a the 
$5 p_{3 / 2}$ peak shows any splitting. (The $5 \mathrm{p}_{3 / 3}$ double peak structure at high $\mathrm{Xe}$ coverages is not due to an $m_{j}$-splitting but arises from Xe on Au- and Ag-sites, respectively, as does the $5 \mathrm{p}_{1 / 2}$ double peak structure.) Warming this $0.5 \mathrm{ML}$ $\mathrm{Ag} / 1 \mathrm{ML}$ Au film to $275 \mathrm{~K}$ for $10 \mathrm{~min}$ results in the PAX-spectra from fig. 7b. There is only very little intensity from "mixed" sites left (arrow). Instead, a rather sharp $5 \mathrm{p}_{1 / 2}$ peak first grows at $6.8 \mathrm{eV}$ (Xe on $\mathrm{Au}$ ) followed by a second also rather sharp $5 p_{1 / 2}$ peak at $7.5 \mathrm{eV}$ ( $\mathrm{Xe}$ on $\mathrm{Ag}$ ). The $5 \mathrm{p}_{3 / 2}$ peak begins to show indication of a double peak structure (shoulder at low binding energies). These spectra from fig. $7 \mathrm{~b}$ are in marked contrast to those shown in fig. 6a. Both figures relate to films which were annealed at $275 \mathrm{~K}$. In the first case $(0.3 \mathrm{ML} \mathrm{Au} / 1 \mathrm{ML} \mathrm{Ag})$ this temperature is enough to activate penetration of $\mathrm{Au}$ atoms into the $\mathrm{Ag}$ underlayer. In the second case $(0.5 \mathrm{ML} \mathrm{Ag} / 1 \mathrm{ML}$ $\mathrm{Au}$ ), however, the $\mathrm{Ag}$ atoms do not yet exchange site with $\mathrm{Au}$ atoms from the first layer, but rather coalesce and form extended 2D Ag islands on the $\mathrm{Au}$ underlayer as suggested by the negligible number of ("mixed") boundary sites (arrow) as well as the improved order in the Xe overlayer ( $5 \mathrm{p}_{3 / 2}$ splitting).

Further annealing of the $0.5 \mathrm{ML} \mathrm{Ag} / 1 \mathrm{ML}$ Au system at $350 \mathrm{~K}$ leaves the $5 \mathrm{p}_{1 / 2}$ peak at $6.8 \mathrm{eV}$ (Xe on $\mathrm{Au}$ ) uneffected (fig. $7 \mathrm{c}$ ). The second $5 \mathrm{p}_{1 / 2}$ signal now peaks at $7.3 \mathrm{eV}$, and can no longer be assigned to $\mathrm{Xe}$ on pure $\mathrm{Ag}$ islands but corresponds to a large number of "mixed" sites, which, however, are now populated at higher Xe coverages, in contrast to the "mixed" sites (6.8 $\left.\mathrm{eV}<E_{\mathrm{B}}^{\mathrm{F}}\left(5 \mathrm{p}_{1 / 2}\right)<7.5 \mathrm{eV}\right)$ in fig. 7a. Therefore we assign the "mixed" sites from fig. $7 \mathrm{c}$ to flat alloy-sites created by intermixing between the $\mathrm{Ag}$ islands (concluded above from fig. 7b) and the Au underlayer.

Finally annealing at 760 to $10 \mathrm{~min}$ causes the formation of a more or less homogeneous AgAu alloy throughout both layers as judged by the single $5 \mathrm{p}_{1 / 2}$ signal in fig. $7 \mathrm{~d}$. The continuously increasing $5 \mathrm{p}_{1 / 2}$ peak width with increasing Xe coverage may be taken as an indication for the successive population of more and more Ag-rich sites (see below).

The above described observations from the (integral) PAX-spectra in figs. $6 a-6 d$ and $7 a-7 d$ can be refined somewhat by taking difference spectra between pairs of consecutive traces. Examples of such difference spectra as obtained from figs. 7a-7d are shown in figs. $8 \mathrm{a}-8 \mathrm{~d}$ and are called "incremental spectra", because each one of them corresponds to an addition to the $\mathrm{Xe}$ coverage (increment). These incremental spectra accentuate the successive population of different surface sites in the order of decreasing Xe adsorption energy, and help to isolate the spectral characteristics of the various kinds of surface sites. For instance, fig. 8a shows more clearly the initial saturation of the "mixed" step-like sites on this surface before the Au sites and then the Ag sites are populated. Obviously, the adsorption energy $E_{\text {ad }}$ of the Xe follows the sequence $E_{\text {ad }}$ (step) $>E_{\text {ad }}(\mathrm{Au})>E_{\text {ad }}(\mathrm{Ag})$. In fig. $8 \mathrm{~b}$ (obtained from $7 \mathrm{~b}$ ) the obvious splitting of the $5 \mathrm{p}_{3 / 2}$ signal of $\mathrm{Xe}$ on $\mathrm{Ag}$ (upper two increments) supports much clearer the extended island structure of the $\mathrm{Ag}$ than fig. $7 \mathrm{~b}$. 

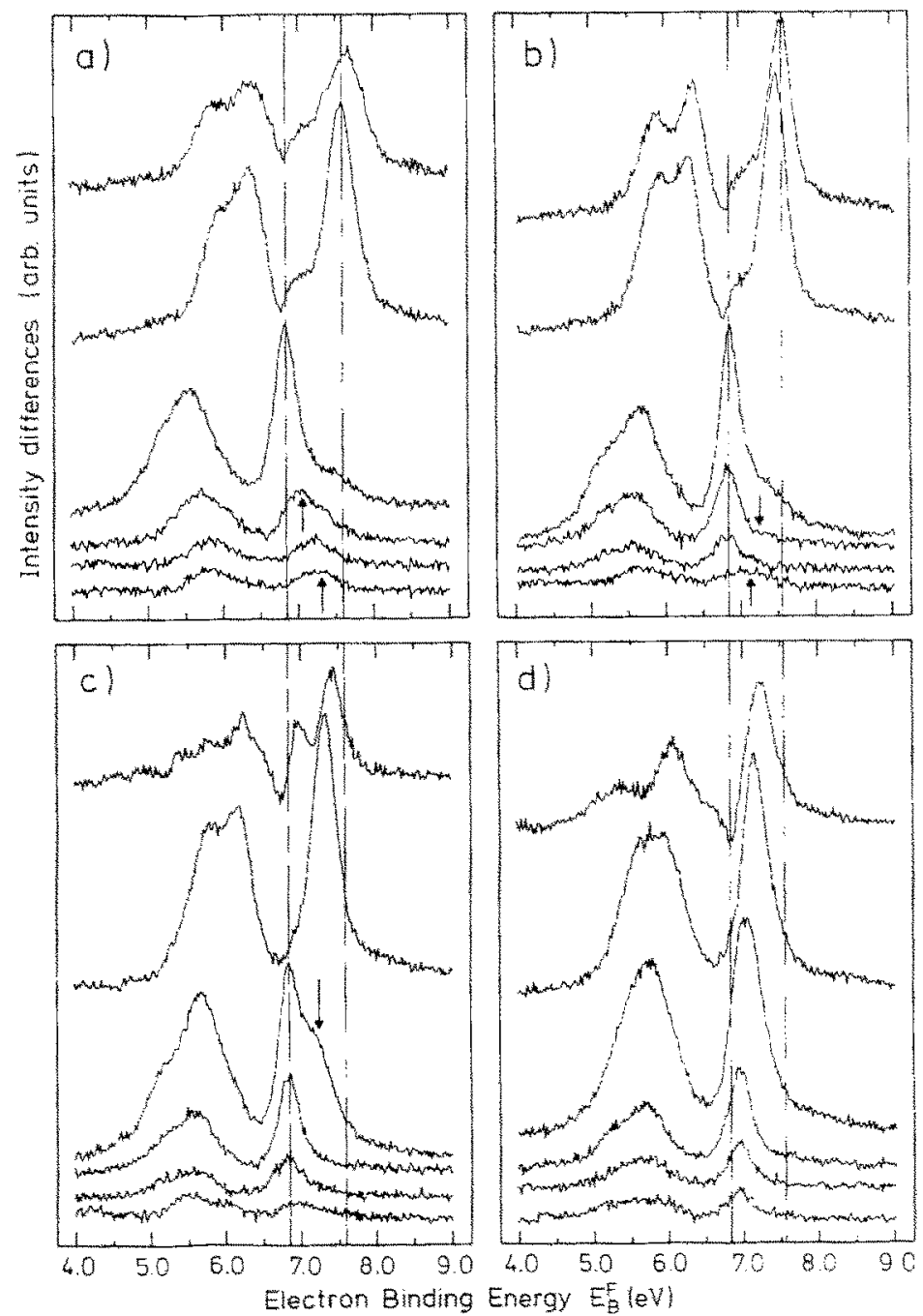

Fig. 8. Difference spectra between successive traces from the corresponding panel in fig. 7 . Each difference spectrum corresponds to an addition to the Xe coverage and is therefore termed "incremental spectrum". These incremental spectra accentuate the successive population of inequivalent surface sites.

Also fig. $8 \mathrm{c}$ improves the splitting of the $5 \mathrm{p}_{3 / 2}$ signal, and finally fig. $8 \mathrm{~d}$ explains the continuous $5 \mathrm{p}_{1 / 2}$ peak broadening in fig, $7 \mathrm{~d}$ as a continuous peak shift to higher binding energy, probably due to a continuous change in AgAu composition of the successively occupied surface sites. The increase of $E_{\mathrm{B}}^{\mathrm{F}}\left(5 \mathrm{p}_{1 / 2}\right)$ with increasing Xe coverage suggests a successive population of 
more and more Ag-rich sites in agreement with the relative adsorption energies (see above).

Since the incremental spectra have the tendency to isolate the spectral properties of Xe atoms adsorbed at individual types of surface sites, they can be used advantageously to establish the fit-parameters for the related partial $5 \mathrm{p}_{3 / 2,1 / 2}$ spectra, as described in the following section.

\subsubsection{PAX-spectra - quantitative aspects}

The quantitative analysis of the PAX-spectra from figs. 6 and 7 is based on a decomposition procedure as follows: First the incremental spectra corresponding to figs. $6 \mathrm{a}-6 \mathrm{~d}$ (not displayed here) and from figs. $8 \mathrm{a}-8 \mathrm{~d}$ were fitted in the order of increasing Xe coverage with a set of three Lorentzian functions per Xe state as depicted in fig. 4 and discussed earlier. The thus determined electron hinding energies per Xe state where then used as input to repeat the fit procedure with the integral spectra shown in figs. $6 \mathrm{a}-6 \mathrm{~d}$ and figs. $7 \mathrm{a}-7 \mathrm{~d}$ in order to find the partial intensities for all Xe states contributing to the respective Xe monolayer spectrum. As explained before the $\mathrm{Xe}\left(5 \mathrm{p}_{1 / 2}\right)$ electron binding energy per Xe state is a measure of the local work function at the corresponding kind of surface site, while the partial intensity per Xe state provides the relative concentration of this particular type of surface site.

Examples of the finally obtained best fits of Xe monolayer PAX spectra are displayed in fig. 9 for the two most important situations in the present study, namely the $0.3 \mathrm{ML} \mathrm{Au} / 1 \mathrm{ML} \mathrm{Ag}$ system annealed at $275 \mathrm{~K}$ (fig. 9a) and the $0.5 \mathrm{ML} \mathrm{Ag} / 1 \mathrm{ML}$ Au system annealed at $275 \mathrm{~K}$ likewise (fig. 9b). Qualitatively the spectral distinction between the two systems could hardly be more clearcut: in the first case the single $5 p_{1 / 2}$ peak suggests intermixing between $\mathrm{Ag}$ and $\mathrm{Au}$, while in the second case the two $5 \mathrm{p}_{1 / 2}$ peaks indicate the persistance of pure Au and pure Ag. Quantitatively, the best fit to spectrum 9a results in three $X e$ states, which, based on their $5 p_{1 / 2}$ electron binding energies, suggest $30 \%$ of the Xe atoms (of a complete Xe monolayer) to sit on pure $\mathrm{Ag}$ sites, while $(61 \%+9 \%)$ sit on "mixed" sites effected by $\mathrm{Ag}$ and $\mathrm{Au}$. Certainly no Xe state characteristic of pure $\mathrm{Au}$ is found $\# 2$. The best fit to spectrum $9 \mathrm{~b}$ requires four Xe states, with $35 \%$ of the atoms emitting from pure $\mathrm{Au}$ sites, $54 \%$ of the Xe atoms sitting on pure $\mathrm{Ag}$ sites, and $(5 \%+6 \%)$ of the intensity coming from "mixed" sites. We do not claim to know the exact assignment of the various "mixed" states (they were simply needed in order to account for the broad emission at these intermediate energies reflecting a distribution in structure and composition of these sites), but we do claim to be able do distinguish quantitatively between the three classes of sites on the respective surface, namely purc Au-, pure $\mathrm{Ag}$ - and "mixed" sites.

\footnotetext{
$\# 2$ According to our long experience these percentages are accurate within $\pm 5 \%$.
} 

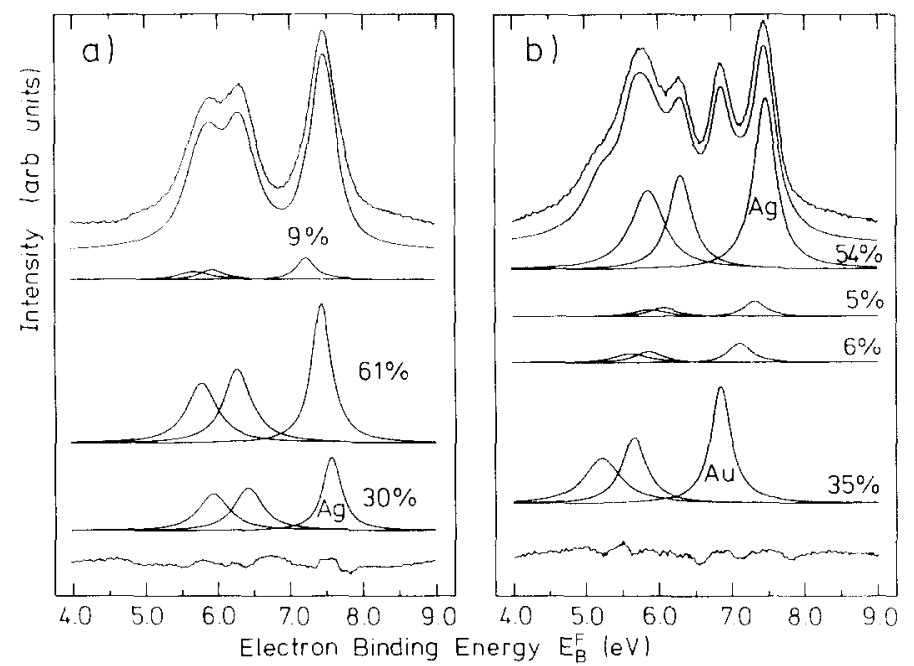

Fig. 9. Examples for the best fits of Xe monolayer PAX spectra (using tripletts of Lorentzian functions as defined in fig. 4 for (a) a $0.3 \mathrm{ML} \mathrm{Au} / 1 \mathrm{ML}$ Ag film on Ru(001) annealed for $10 \mathrm{~min}$ at $275 \mathrm{~K}$, and (b) a $0.5 \mathrm{ML} \mathrm{Ag} / 1 \mathrm{ML}$ Au film on $\mathrm{Ru}(001)$ annealed for $10 \mathrm{~min}$ at $275 \mathrm{~K}$ likewise. Note the clear difference in the $5 p_{1 / 2}$ peak shape, namely a single peak in panel (a) and a double peak in panel (b). The different sets of three Lorentzian lines correspond to Xe atoms adsorbed at different surface sites, and the percentages represent their relative surface concentrations (see text).

A compilation of the fit results from all Xe monolayer PAX-spectra shown in figs. $2 a, 2 b, 6 a-6 d$ and $7 a-7 d$ is given in fig. 10 . At the top the electron binding energy scale is devided into three regimes, namely two vertical lines at $\sim 6.8 \mathrm{eV}$ and $\sim 7.6 \mathrm{eV}$ indicating the positions of the $\mathrm{Xe}\left(5 \mathrm{p}_{1 / 2}\right)$ signal on a pure $\mathrm{Au}$ (fig. $2 \mathrm{a}$ ) and a pure $\mathrm{Ag}$ monolayer (fig. 2b) on $\mathrm{Ru}(001)$, respectively, and a broad regime between 7.0 and $7.4 \mathrm{eV}$, which encompases the $\mathrm{Xe}\left(5 \mathrm{p}_{1 / 2}\right)$ binding energies from all kinds of "mixed" sites including a substitutional AgAu alloy surface (see line AgAu in the center). The black bars mark the $5 \mathrm{p}_{1 / 2}$ position as they came out from the decomposition of the experimental $\mathrm{Xe}$ monolayer spectra. As mentioned above no further attempt is made in order to assign the various "mixed" states from one surface. The percentages in fig. 10 denote the relative intensity of each decomposed state. The small atomistic models are to visualize the conclusions about the chemical distribution and structure of the different treated $(\mathrm{Au}+\mathrm{Au})$-films.

A careful inspection of the numbers in fig. 10 reveals several very interesting details which go much beyond the qualitative observations described earlier. As pointed out before, a temperature of $275 \mathrm{~K}$ suffices to activate intermixing between the $0.3 \mathrm{ML} \mathrm{Au}$ overlayer with the $1 \mathrm{ML} \mathrm{Ag}$ underlayer. The numbers in the upper half of fig. 10, however, further suggest that always 


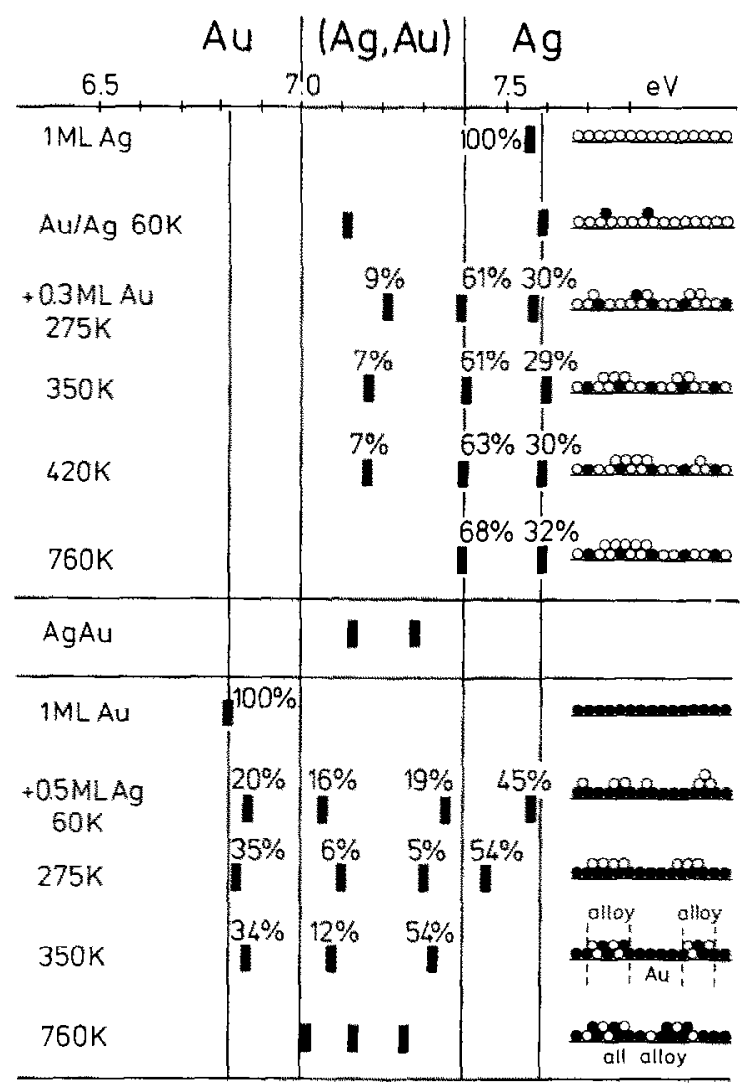

Fig. 10. Compilation of $5 p_{1 / 2}$ electron binding energies (black bars) and relative intensities (percentages) of coexisting Xe adsorption states on differently annealed (Ag $+\mathrm{Au}$ ) tilms on a Ru(001) substrate, as obtained from a decomposition of all the Xe monolayer PAX-spectra shown in figs. $6 \mathrm{a}-6 \mathrm{~d}$ and $7 \mathrm{a}-7 \mathrm{~d}$. These data support the small structure models shown on the right-hand side.

$\sim 30 \%$ of the surface are Ag-like, even after annealing at the very high temperature of $760 \mathrm{~K}$ (see shoulder in spectrum 6d).

These $30 \%$ agree with the amount of $0.3 \mathrm{ML}$ Au originally deposited. This strongly suggests, that the adsorbed $\mathrm{Au}$ atoms have completely penetrated into the $\mathrm{Ag}$ underlayer, thereby displacing an equivalent number of $\mathrm{Ag}$ atoms into the second layer where they then form monatomically thick islands of pure Ag. Furthermore, the corresponding relative intensities of the "mixed" states are compatible with a lateral growing of these pure $\mathrm{Ag}$ islands with increasing annealing temperature (see the atomic models), because the number of island boundary sites decreases from $9 \%$ to $\sim 0 \%$. The high value of the $\operatorname{Xe}\left(5 \mathrm{p}_{1 / 2}\right)$ 
electron binding energy (7.4 eV) of the final "mixed" state (68\% after $760 \mathrm{~K})$ is suggestive of a Ag-rich alloy in the first layer.

Also in the second experiment with the Au underlayer two interesting details may be concluded from the numbers compiled in the lower half of fig. 10. Firstly, upon annealing from 60 to $275 \mathrm{~K}$ the relative intensity of the $\mathrm{Xe}$ state on pure $\mathrm{Ag}$ sites increases from $45 \%$ to $54 \%$, the latter being in good agreement with the actual coverage as determined by Ag-TDS after the experiment. This increase may be indicative of the existence of small $\mathrm{Ag}$ clusters at $60 \mathrm{~K}$ which spread out upon warming to $275 \mathrm{~K}$ as depicted in the small atomistic models. Secondly, annealing from $275 \mathrm{~K}$ to $350 \mathrm{~K}$ does not change the intensity of the Xe state on pure Au sites (34\%), while on the other hand the $\mathrm{Xe}(\mathrm{Ag})$ signal vanishes. This is a strong indication that the initial $A g A u$ alloy formation proceeds via site-exchange only within the area of the original Ag islands which were produced on top of the underlayer at $275 \mathrm{~K}$. This suggests also, that the activation energy for this site-exchange normal to the surface is smaller than the 2D heat of sublimation of the Ag islands on Au. Only very high temperature treatment at $760 \mathrm{~K}$ leads to a homogenization of the AgAu alloy parallel to the surface.

\section{Summary and conclusions}

As a result of these model experiments we find, that an Ag/ Au-interface (on $\mathrm{Ru}$ ) is thermally more stable than an $\mathrm{Au} / \mathrm{Ag}$ interface. In the first case (initial Au underlayer) $\mathrm{Ag}$ does not penetrate into the Aul layer below $275 \mathrm{~K}$. Conversely, in the second case (initial Ag underlayer) the $\mathrm{Au}$ atoms exchange site with underlying $\mathrm{Ag}$ atoms already at $275 \mathrm{~K}$, leading to the formation of a monolayer of an $\mathrm{Ag}_{0.7} \mathrm{Au}_{0.3}$ alloy covered with pure, monatomically thick $\mathrm{Ag}$ islands. This remarkable difference appears easily conceivable in terms of the energy terms involved:

(1) The adsorption energy of $\mathrm{Au}$ on $\mathrm{Ru}(001)$ is significantly higher than that of $\mathrm{Ag}$ [9].

(2) The surface free energy of $\mathrm{Ag}$ is lower than that of $\mathrm{Au}$ [17].

(3) The lateral interaction energy between adsorbed Ag atoms (on Ru(001)) is attractive [9].

(4) The heat of formation of AgAu alloys is slightly exothermic [18].

The first two terms favor $\mathrm{Au}$ atoms to get in contact with the Ru substrate and Ag atoms to be exposed in the second (outer) layer. This process, however, will compete with the exothermicity of the AgAu alloy formation which tends to maximize the number of $\mathrm{Ag}-\mathrm{Au}$ bonds. Finally, the attractive $\mathrm{Ag}-\mathrm{Ag}$ interaction explains the formation and the growth of the $2 \mathrm{D} \mathrm{Ag}$ islands in the second layer of the first system (initial Ag underlayer). 
A further conclusion from the present study certainly is, that the results once again demonstrate what kind of detailed informations can be obtained by means of the PAX-method in order to characterize the structure and structural transformations at heterogeneous surfaces on an atomic scale. Of course, the $(\mathrm{Ag}+\mathrm{Au})$-system was only chosen as a case study. The investigations described here can be carried over the other metal/metal combinations.

\section{Acknowledgements}

This work was supported by the Deutsche Forschungsgemeinschaft (SFB 128). J.W.N. is supported by a Huygens-fellowship from the Netherlands Organization for the Advancement of Pure Research (ZWO) and P.D. thanks the Centre National de la Recherche Scientific (CNRS), France for granting his stay in Germany.

\section{References}

[1] A. Clarke, P.J. Rous, M. Arnott, G. Jennings and R.F. Willis, Surface Sci. 192 (1987) L843.

[2] W. Dürr, R. Germar, D. Pescia, M. Taborelli, O. Paul and M. Landolt, to be published.

[3] M. Taborelli, R. Allenspach, G. Boffa and M. Landolt, Phys. Rev. Letters 56 (1986) 2869.

[4] K. Wandelt, in: Thin Metal Films and Gas Chemisorption, Ed. P. Wissmann (Elsevier, Amsterdam, 1987) p. 280.

[5] J.W. Niemantsverdriet, K. Markert, P. Dolle and K. Wandelt, Surface Sci. $211 / 212$ (1989) 414.

[6] K. Wandelt, J. Hulse and J. Küppers, Surface Sci. 104 (1981) 212.

[7] K. Wandelt, S. Daiser, R. Miranda and H.-J. Forth, J. Phys. E (Sci. Instr.) 17 (1984) 22.

[8] H. Herz, H. Conrad and J. Küppers, J. Phys. E (Sci. Instrum.) 12 (1979) 369.

[9] J.W. Niemantsverdriet, P. Dolle, K. Markert and K. Wandelt, J. Vacuum Sci. Technol. A 4 (1987) 875.

[10] K. Markert, P. Dolle, J.W. Niemantsverdriet and K. Wandelt, J. Vacuum Sci. Technol., in press.

[11] A. Jablonski, S. Eder and K. Wandelt, Appl. Surface Sci. 22/23 (1985) 309.

[12] K. Horn, M. Scheffler and A.M. Bradshaw, Phys. Rev. Letters 44 (1978) 822.

[13] M. Scheffler, K. Horn, A.M. Bradshaw and K. Kambe, Surface Sci. 80 (1979) 69.

[14] K. Kambe, Surface Sci. 105 (1981) 95.

[15] J.W. Niemantsverdriet, K. Markert and K. Wandelt, Vacuum, in press.

[16] R.J. Behm, C.R. Brundle and K. Wandelt, J. Chem. Phys. 85 (1996) 1061.

[17] A.R. Miedema and J.W.F. Dorleijn, Surface Sci. 95 (1980) 447.

[18] P. Hultgren, R.L. Orr, P.D. Anderson and K.K. Kelley, in: Selected Values of Thermodynamic Properties of Metals and Alloys (Wiley, New York, 1963 ) p. 341. 